\title{
Corrosion Behaviour of Iron and AISI 304 Stainless Steel in Tungstate Aqueous Solutions Containing Chloride
}

\author{
Denise S. Azambuja ${ }^{*, a}$, Emilse M. A. Martini ${ }^{a}$ and Iduvirges L. Müller ${ }^{b}$ \\ ${ }^{a}$ Instituto de Química, ${ }^{b}$ Escola de Engenharia, Universidade Federal do Rio Grande do Sul, Av. Bento Gonçalves, \\ 9500, CP 9500, 91591-970 Porto Alegre - RS, Brazil
}

\begin{abstract}
O comportamento do ferro e do aço inoxidável AISI 304 frente à corrosão em solução aquosa de tungstato de sódio em presença de cloreto foi investigado usando as técnicas de voltametria cíclica, medidas de potencial de circuito aberto e impedância eletroquímica. Os resultados mostraram que a ação inibidora do ânion tungstato está relacionada com sua adsorção sobre a superfície eletrodódica e depende marcadamente da presença de oxigênio dissolvido no meio. Filmes formados por polarização anódica a baixas velocidades de varredura de potencial e rotação do eletrodo são mais estáveis permitindo um decréscimo na taxa de corrosão. Medidas de impedância eletroquímica em potencial de circuito aberto mostraram que a ação inibidora do tungstato é consideravelmente favorecida em tempos de imersão prolongados.
\end{abstract}

The corrosion behavior of iron and AISI 304 stainless steel in aqueous tungstate solutions containing chloride ion was investigated by cyclic voltammetry, open circuit measurements and impedance spectroscopy. The obtained results point out that the inhibitive performance of tungstate depends on the presence of dissolved oxygen, being strongly related to the adsorption of this anion on the surface of the electrode. Under anodic polarization, at low sweep rate and electrode rotation the passive film is more stable and the corrosion rate decreases. At the open circuit potential, the EIS data have clearly demonstrated that for longer immersion times the tungstate inhibitive action is considerably improved.

Keywords: tungstate, iron, stainless steel, pitting

\section{Introduction}

The inhibitive effect of chromate and nitrite on the corrosion of iron has been extensively studied, since 1950. Evans and Hoar ${ }^{1}$ have ascribed the inhibitive effect of the chromate ion to its oxidizing power. Pryor and $\mathrm{Cohen}^{2}$ studied the effect of molybdate and tungstate ions, which are weaker oxidizing agents than the chromate anion, on the corrosion of iron and noted that their inhibitive behavior greatly depend on the presence of dissolved oxygen. A comparative study regarding the effect of the addition of pertechnetate, chromate, molybdate and tungstate ions on the iron corrosion potential was reported by Sympson and Cartledge. ${ }^{3}$ All four inhibitors maintained the iron electrodes at potentials nobler than the Flade potential in the presence of dissolved air, but only the pertechnetate ion did the same in deaerated solutions.

\footnotetext{
* e-mail: denise@iq.ufrgs.br
}

Among these inhibitors, it is well known that chromate is the most effective. ${ }^{4}$ However, its use has been drastically reduced in recent years due to its toxicity.

The investigations of more environmentally acceptable corrosion inhibitors are of great practical interest. In this connection, studies on the inhibitive behavior of molybdate, tungstate and, at a lesser extent, of vanadate, have been carried out. Kolman and Taylor ${ }^{5}$ reported that the steel corrosion rate decreases with increasing the molybdate concentration and the electrode rotation speed due to a higher rate of oxygen transport from the solution to the electrode surface. Fujioka et al. ${ }^{6}$ explained the behavior of oxidizing inhibitors, among them tungstate and molybdate, on iron and stainless steel pitting corrosion based upon the hard and soft acid base theory (HSAB). In this model the oxidant anion and the $\mathrm{Fe}^{+3}$ cation are classified as a hard base and a hard acid respectively, leading to the formation of stable salts or complexes on the electrode surface. A previous comparative study on the behavior of molybdate, vanadate and tungstate ${ }^{7}$ 
showed that under static conditions the effectiveness of these anions decrease in the order $\mathrm{WO}_{4}^{-2}>\mathrm{MoO}_{4}^{-2}>\mathrm{VO}_{3}$. Under electrode rotation, the performance of these anions is altered: $\mathrm{WO}_{4}^{-2}>\mathrm{VO}_{3}^{-}>\mathrm{MoO}_{4}^{-2}$. Abd El Kader et al. ${ }^{8,9}$ have explained the corrosion inhibition of mild steel by sodium tungstate in neutral solution containing $\mathrm{NaCl}$ on the basis of a competitive adsorption process of both anions, differing in their adsorption energy. Depending on the relative concentration of chloride and tungstate in the electrolyte, generalized or localized corrosion occurs.

The present work is devoted to study the corrosion behavior of iron and AISI 304 stainless steel in neutral aqueous solutions of tungstate containing chloride ions, by using open circuit potential measurements, cyclic voltammetry and electrochemical impedance spectroscopy.

\section{Experimental}

Disc working electrodes of $0.5 \mathrm{~cm}$ diameter were made from high purity iron (99.99\%, Aldrich) and AISI 304 stainless steel (Goodfellow) with the following chemical composition (wt \%): Ni 10, Cr 18, and balance Fe embedded in epoxy resin. To compare the open circuit measurements chromium and nickel (from Goodfellow) electrodes were also used. Before each test, the electrode was mechanically polished up to 1200 grit with emery papers and repeatedly rinsed with double distilled water. Electrolyte solutions were made of sodium tungstate in the concentration range of 0.01 to $0.10 \mathrm{~mol} \mathrm{~L}^{-1}$ with and without the addition of $\mathbf{x}$ mol L $\mathrm{L}^{-1} \mathrm{NaCl}(\mathbf{x}=0.01 ; 0.05$ and 0.10$)$ prepared from analytical grade reagents with doubly distilled water. The measured $\mathrm{pH}$ of these solutions was around 7.5. A saturated calomel electrode (SCE) provided with a Luggin capillary tip was used as reference electrode, and all potentials are referred to it. The auxiliary electrode was a Pt gauze. The experiments were carried out under aerated conditions at $25{ }^{\circ} \mathrm{C}$.

The electrochemical measurements were performed using an AUTOLAB PGSTAT 30/FRA 2 system and an analytical rotator PAR 616. In order to obtain reproducible measurements, the Fe electrodes were electroreduced for $20 \mathrm{~min}$. at $-1.2 \mathrm{~V}$ before each voltammetric test. For the AISI 304 steel electrode reproducible voltammetric curves were obtained without the electroreduction. At least five repeat experiments were carried out for all specimens. The impedance tests were carried out at the open circuit potential in the $10 \mathrm{kHz}-10 \mathrm{mHz}$ frequency range and the amplitude of the sinusoidal voltage was $10 \mathrm{mV}$. The EIS data were analysed using PAR's 3.95 'Equivalent Circuit"software.

\section{Results and Discussion}

\section{Open circuit potential profiles}

Figure 1 shows the open circuit potential $\left(\mathrm{E}_{\text {corr }}\right) v s$. immersion time curves for the $\mathrm{Fe}, \mathrm{Cr}, \mathrm{Ni}$ and AISI 304 steel electrodes in aerated aqueous $0.05 \mathrm{~mol} \mathrm{~L}^{-1} \mathrm{Na}_{2} \mathrm{WO}_{4}$ solution at static conditions. In order to analyze the $\mathrm{E}_{\text {corr }}$ vs. time curves for the stainless steel, measurements were made with $\mathrm{Cr}$ and $\mathrm{Ni}$ electrodes in this medium. For $\mathrm{Fe}$, sometimes an initial decrease of $\mathrm{E}_{\text {corr }}$ was observed before its sustained increase, which may be due to a partial dissolution of the air formed film followed by the posterior growth of a passivating film. For the Ni electrode the $\mathrm{E}_{\text {corr }}$ value remains around $-0.10 \mathrm{~V}$ that corresponds to the active to passive transition region at this $\mathrm{pH} .{ }^{10}$ Increasing the immersion time, the $\mathrm{E}_{\text {corr }}$ shifted to more positive values for the $\mathrm{Cr}$ electrode up to $0 \mathrm{~V}$. The similarity between the AISI 304 and $\mathrm{Cr}$ potential profiles can be explained by assuming that the initial potential rise indicates the formation of an insoluble layer product, probably a $\mathrm{Cr}$ (III)-rich oxide phase on the electrode surface. The anodic shifting of $\mathrm{E}_{\text {corr }}$ can be attributed to the product layer thickening process and to an increase in the resistance of this layer. Drogovska et al. ${ }^{11}$ reported that $\mathrm{Cr}$ and AISI 304 steel in carbonate solution showed a similar behavior at the $\mathrm{E}_{\text {corr }}$ increasing continuously with the exposure time, albeit at a higher rate for $\mathrm{Cr}$. The same behavior was evidenced for the $\mathrm{E}_{\text {corr }} v s$. time curves in the entire range of tungstate concentration solutions employed in this work.

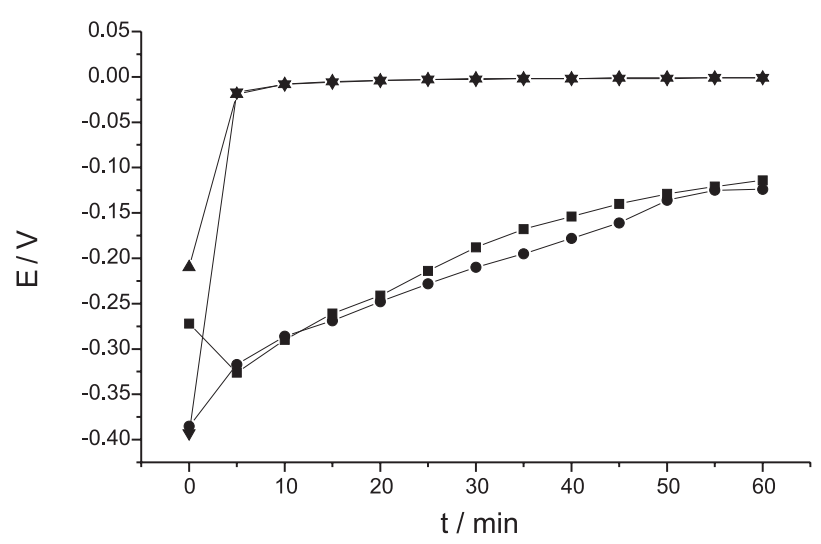

Figure 1. Open circuit potential x time plots for AISI 304, Cr, Ni and $\mathrm{Fe}$ electrodes in $0.05 \mathrm{~mol} \mathrm{~L}^{-1} \mathrm{Na}_{2} \mathrm{WO}_{4}$ solution at static condi-

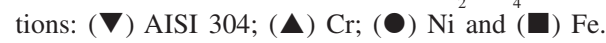

Therefore, after 60 min exposure, the iron and the AISI 304 steel electrodes reached an $\mathrm{E}_{\text {corr }}$ value around -0.15 and $0.01 \mathrm{~V}$, correspondent to the passive potential region of these materials, being not influenced by the electrode rotation (data not shown). 
The open circuit potential vs. time curves for the iron and AISI 304 steel electrodes in a $0.050 \mathrm{~mol} \mathrm{~L}^{-1} \mathrm{Na}_{2} \mathrm{WO}_{4}$ containing 0.050 and $0.10 \mathrm{~mol} \mathrm{~L}^{-1} \mathrm{NaCl}$ at $\omega=0$ and 1000 rpm are given in Figure 2. Concerning the iron, the $\mathrm{E}_{\text {corr }}$ shifts toward the iron passive region, reaching a value around $-0.20 \mathrm{~V}$ at static conditions and $-0.30 \mathrm{~V}$ at 1000 rpm, for both chloride concentrations. This potential rise may be explained admitting that the tungstate anion reacts with iron as soon as the electrode is immersed into the solution. Then a product layer begins to block the metal surface decreasing the anodic dissolution sites, even in presence of chloride. The $\mathrm{E}_{\text {corr }}$ behavior for iron in tungstate solutions containing chloride without electrode rotation was reported by Abd El Kader et al., ${ }^{9}$ where at lower chloride concentration the $\mathrm{E}_{\text {corr }}$ shifting was correlated to a general corrosion and at higher concentrations to a localized corrosion. The present results point out that besides the chloride concentration the mass transport regimen plays a determinant role in this process. Under electrode rotation a competitive process takes place on the electrode surface: at one hand the dissolved oxygen flux is enhanced, which may help the film repair, but also the flux of chloride ions increases stimulating the dissolution. Therefore, the potential increase is much slower under rotation than in quiescent solution. On the other hand, a decrease of the $\mathrm{E}_{\text {corr }}$ value in the first $5 \mathrm{~min}$ was detected for the iron electrode in chloride ion solution, probably due to the partial dissolution of the air formed film. Furthermore, this accentuated initial potential decrease indicates that metal recovery is more slowly in these chloride-containing solutions than in chloride-free ones.

For the AISI 304 steel electrode the $\mathrm{E}_{\text {corr }}$ remains in the passive state, in all tested chloride concentrations and

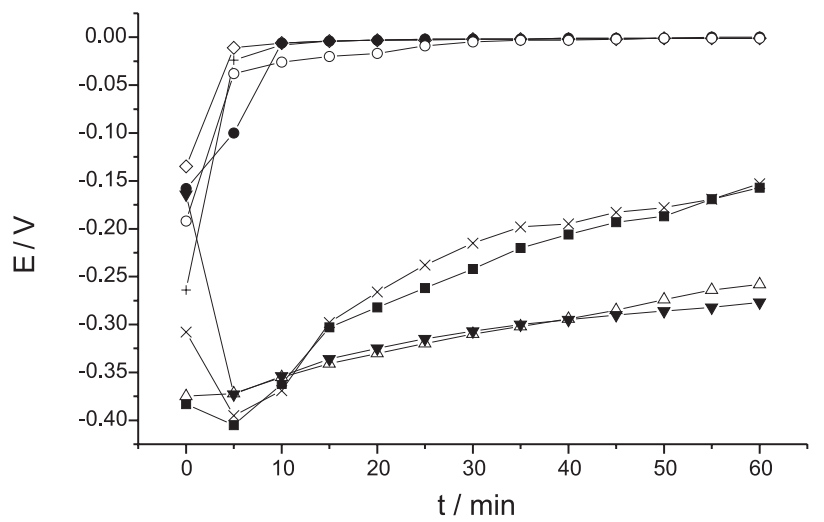

Figure 2. Open circuit potential $\mathrm{x}$ time plots for Fe and AISI 304 electrodes in $0.05 \mathrm{~mol} \mathrm{~L}^{-1} \mathrm{Na}_{2} \mathrm{WO}_{4}$ solution $+\mathrm{x} \mathrm{molL}^{-1} \mathrm{NaCl}$ at static and dynamic conditions: $(\boldsymbol{\square}) \mathrm{Fe}, \mathrm{x}=0.05, \omega=0 ;(\times) \mathrm{Fe}, \mathrm{x}=0.10$, $\omega=0 ;(\triangle) \mathrm{Fe}, \mathrm{x}=0.05, \omega=1000 \mathrm{rpm} ;(\boldsymbol{\nabla}) \mathrm{Fe}, \mathrm{x}=0.10, \omega=1000$ rpm; $(\diamond)$ AISI 304, $x=0.05, \omega=0$; $(+)$ AISI 304, $x=0.10, \omega=0$; (O) AISI 304, $\mathrm{x}=0.05, \omega=1000 \mathrm{rpm}$; (○) AISI 304, $\mathrm{x}=0.10$, $\omega=1000 \mathrm{rpm}$. electrode rotation rate, evidencing that the steel is covered by a stable passive layer. In identical experimental conditions, after 60 minutes exposure, the measured corrosion potential for $\mathrm{Cr}$ reached a constant value, around $-0.03 \mathrm{~V}$. Once more the similarity of the steel and chromium electrode behavior was detected.

\section{Potentiodynamic experiments}

Cyclic voltammograms were run with the iron electrode in an aerated $0.10 \mathrm{~mol} \mathrm{~L}^{-1}$ tungstate solution containing $0.01 \mathrm{~mol} \mathrm{~L}^{-1} \mathrm{NaCl}$, at 0.001 and $0.050 \mathrm{~V} \mathrm{~s}^{-1}$ at $\omega=0$ and $1000 \mathrm{rpm}$. Figure 3 a shows the effect of electrode rotation, keeping constant the scan rate in $0.001 \mathrm{~V} \mathrm{~s}^{-1}$. At static conditions (curve a), the passivity breakdown took place, and a breakdown potential $\left(\mathrm{E}_{\mathrm{B}}\right)$ equal to $0.20 \mathrm{~V}$ was measured. With the electrode rotation, dissolution was observed only at the reverse scan (curve b). At higher sweep rates the pit nucleation occurred independently of the electrode rotation (Figure $3 b$ ).
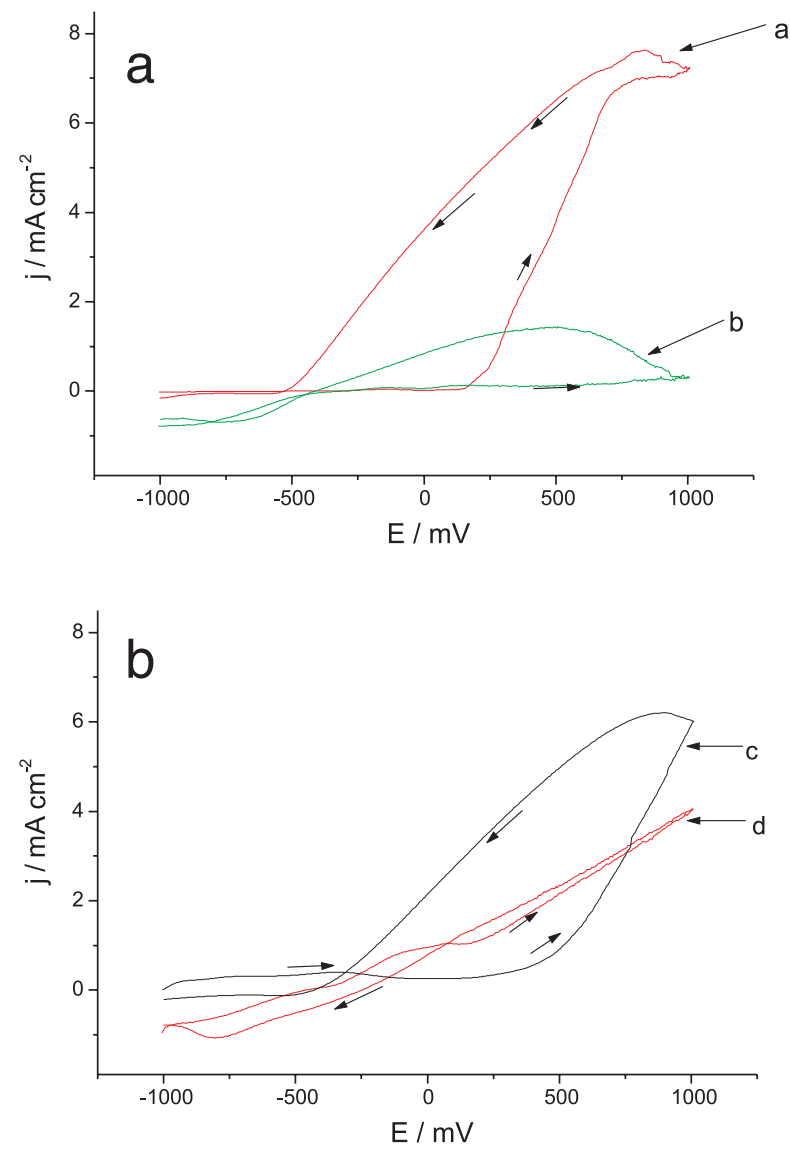

Figure 3. a) Cyclic voltammograms for Fe electrode in $0.10 \mathrm{~mol} \mathrm{~L}^{-1}$ $\mathrm{Na}_{2} \mathrm{WO}_{4}$ solution and $0.01 \mathrm{~mol} \mathrm{~L}^{-1} \mathrm{NaCl}$ at $\mathrm{v}=0.001 \mathrm{~V} \mathrm{~s}^{-1}$ under static and dynamic conditions: (a) $\omega=0$; (b) $\omega=1000 \mathrm{rpm}$; b) Cyclic voltammograms for $\mathrm{Fe}$ electrode in $0.10 \mathrm{~mol} \mathrm{~L}^{-1} \mathrm{Na}_{2} \mathrm{WO}_{4}$ solution and $0.01 \mathrm{~mol} \mathrm{~L}^{-1} \mathrm{NaCl}$ at $\mathrm{v}=0.050 \mathrm{~V} \mathrm{~s}^{-1}$ under static and dynamic conditions: (c) $\omega=0$; (d) $\omega=1000 \mathrm{rpm}$. 
Once the film was broken down and pitting corrosion started, drastic dissolution of iron occurred in the acidified $\mathrm{Cl}^{-}$ion medium within the pits.

The effect of rotation in inhibiting the pitting onset may be related to the increased mass transport resulting in an easier adsorption of the inhibitive species due to its higher concentration at the surface. Moreover, a possibly higher concentration of oxygen would favor the inhibition of pitting corrosion. In fact, in both curves $b$ and $d$ of Figure 3 , the oxygen reduction reaction was clearly detected at $\omega=1000 \mathrm{rpm}$, independently of the sweep rate. Therefore, it can be assumed that during the anodic sweep, at lower sweep rates the inhibitor is adsorbed preferentially compared to $\mathrm{Cl}^{-}$, allowing the $\mathrm{WO}_{4}^{-2}$ adsorption on the defects of the product layer and producing a more protective film.

At higher metal dissolution rate, more adsorbed inhibitor can be dessorbed exposing the bare metal to further attack, making the dessorption rate higher than the adsorption one. ${ }^{12}$ These trends reflect the competitive nature of the adsorption process between the aggressive and the inhibiting anions. Moreover, this confirms the strong dependence of pitting induction time from the anodic polarization program. ${ }^{13}$

The AISI 304 steel voltammograms performed in a $0.010 \mathrm{~mol} \mathrm{~L}^{-1} \mathrm{Na}_{2} \mathrm{WO}_{4}$ solution, at $0.050 \mathrm{~V} \mathrm{~s}^{-1}$ in presence of chloride, show that, keeping constant the sweep rate, a localized corrosion takes place on the electrode, depending on the chloride concentration and mass transport regimen (Figure 4). Thus, for $[\mathrm{NaCl}]=0.01 \mathrm{~mol} \mathrm{~L}^{-1}$ pits are not detected. Increasing chloride ion concentration up to $0.05 \mathrm{~mol} \mathrm{~L}^{-1} \mathrm{NaCl}$ results in the film breakdown, with a lower dissolution rate and a more positive $\mathrm{E}_{\mathrm{B}}$ at $1000 \mathrm{rpm}$.

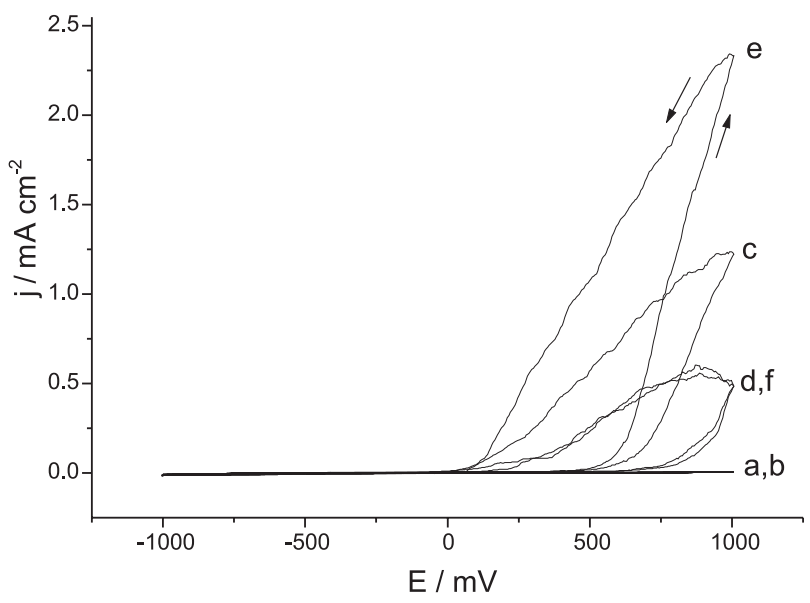

Figure 4. Cyclic voltammograms for AISI 304 electrode in 0.010 mol L-1 $\mathrm{Na}_{2} \mathrm{WO}_{4}$ solution $+\mathrm{x}$ molL ${ }^{-1} \mathrm{NaCl}$ at static and dynamic conditions at $v=0.050 \mathrm{~V} \mathrm{~s}^{-1}$ : (a) $\mathrm{x}=0.01, \omega=0$; (b) $\mathrm{x}=0.01, \omega=$ $1000 \mathrm{rpm}$, (c) $\mathrm{x}=0.05, \omega=0$; (d) $\mathrm{x}=0.05, \omega=1000 \mathrm{rpm}$; (e) $\mathrm{x}=$ $0.10, \omega=0$ and (f) $\mathrm{x}=0.10, \omega=1000 \mathrm{rpm}$.
The deleterious effect of higher aggressive anion concentration is more pronounced at static conditions. Probably the electrode rotation promotes the transport of the acidified chloride solution from within the pit to the external medium and also of the dissolved oxygen from the bulk electrolyte to the electrode surface. Consequently, the pit propagation rate decreases.

\section{Impedance measurements}

The electrochemical impedance measurements of iron were carried out at the corrosion potential in aerated solutions of tungstate, at several immersion times, with and without chloride addition.

The effect of chloride concentration on the Bode plots for iron after 14 days of immersion in $0.10 \mathrm{~mol} \mathrm{~L}^{-1} \mathrm{Na}_{2} \mathrm{WO}_{4}$ is given in Figure 5. For a $0.01 \mathrm{~mol} \mathrm{~L}^{-1} \mathrm{NaCl}$ the diagram presents the highest value of the polarization $\left(\mathrm{R}_{\mathrm{p}}\right)$ corresponding to a passive electrode. On increasing chloride concentration, besides the $\mathrm{E}_{\text {corr }}$ shifting towards the more active region (from -0.24 to $-0.40 \mathrm{~V}$ ), the film resistance decreases and the $\log |\mathrm{Z}| v s$. log f slope varies (from -0.79 to -0.45). The capacitance (C) was calculated by plotting Z'vs. $\omega Z$ ', over the entire frequency range including the contribution of the capacitance of each interface and that of the film. ${ }^{14}$ The advantage of this procedure is that the capacitance can be obtained in systems which are mainly controlled by diffusion and therefore a Warburg impedance is predominant. A value of $1.3 \mathrm{mF} \mathrm{cm}^{-2}$ for the calculated capacitance indicates that diffusion processes within the pores take place, being the overall process mass-transport controlled. ${ }^{15,16}$ However, even in the more concentrated chloride solution the film resistance remains high, which can be attributed to the

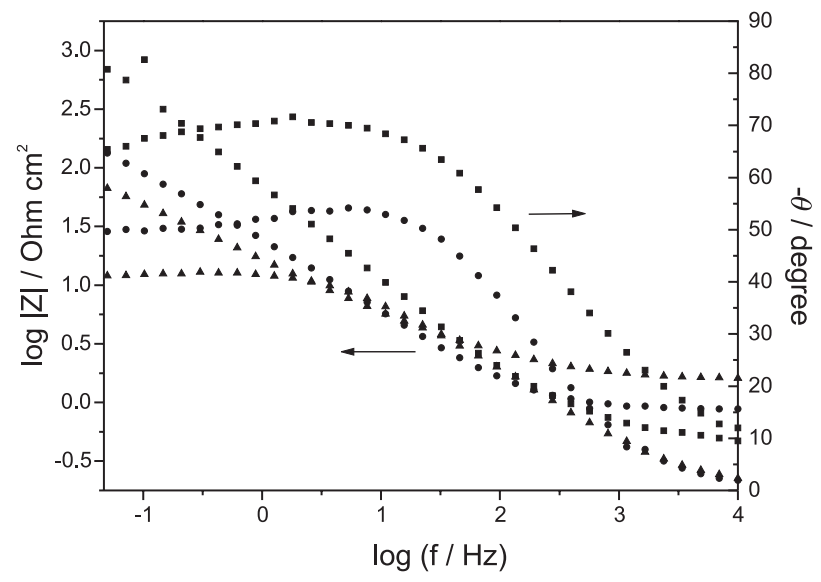

Figure 5. Effect of chloride concentration on the Bode plots for Fe electrode after 14 days of immersion at the $\mathrm{E}_{\text {corr }}$ in a $0.10 \mathrm{~mol} \mathrm{~L}^{-1}$ $\mathrm{Na}_{2} \mathrm{WO}_{4}$ solution, with $0.010(\boldsymbol{\Delta}), 0.050(\boldsymbol{\bullet})$ and $0.10 \mathrm{~mol} \mathrm{~L}^{-1}$ $\mathrm{NaCl}(\mathbf{\square})$. 
adsorbed $\mathrm{WO}_{4}^{-2}$ at the defects of the passive film and within the pit, by repairing both of them and leading to a more stable passivating layer.

Due to the difficulty in determining the polarization resistance the resistive component of the impedance measured at a sufficiently low fixed frequency has been employed to evaluate the corrosion rate. ${ }^{17}$ According to Magalhães et al. ${ }^{17}$ the resistance measured at $3 \mathrm{mHz}$ can be used to obtain comparative information, which can be correlated with the inhibitor at different experimental conditions. Considering that in the present work the lowest frequency used was $10 \mathrm{mHz}$, the resistance measured at this point was used to evaluate qualitatively the corrosion behaviour. Thus, the resistance at $10 \mathrm{mHz}\left(\mathrm{R}_{10 \mathrm{mHz}}\right)$ for the stainless steel after 1 day exposure in $0.01 \mathrm{~mol} \mathrm{~L}^{-1} \mathrm{Na}_{2} \mathrm{WO}_{4}$ solution containing 0.01 and $0.10 \mathrm{~mol} \mathrm{~L}^{-1} \mathrm{NaCl}$ were 6.42 and $17.74 \mathrm{k} \Omega \mathrm{cm}^{2}$, respectively, being the corrosion potential equal to $-0.21 \mathrm{~V}$ in both cases. Increasing the immersion time to 6 days and the tungstate concentration to $0.05 \mathrm{~mol} \mathrm{~L}^{-1}$ the $\mathrm{R}_{10 \mathrm{mHz}}$ measured in 0.01 and $0.10 \mathrm{~mol} \mathrm{~L}^{-1}$ $\mathrm{NaCl}$ were $48.92 \mathrm{k} \Omega \mathrm{cm}^{2}$ and $37.25 \mathrm{k} \Omega \mathrm{cm}^{2}$, respectively. These features can be related to two main factors. First, the tungstate anion shows buffering properties, ${ }^{18}$ consuming the $\mathrm{H}^{+}$ions produced in the hydrolysis of metallic cations, suppressing the local acidification according to the following reactions:

$\mathrm{WO}_{4}^{2-}+\mathrm{H}^{+} \leftrightarrow \mathrm{HWO}_{4}$

$\mathrm{HWO}_{4}^{-}+\mathrm{H}^{+}+2 \mathrm{H}_{2} \mathrm{O} \leftrightarrow \mathrm{W}(\mathrm{OH})_{6}$

Second, several tungstate polymeric species ${ }^{18,19}$ are formed with the metallic cations which can be adsorbed on the metal surface therefore repairing the defects and pits, producing a stable passive film.

The effect of longer immersion time on the corrosion behavior was evaluated. Figure 6 gives the Bode spectra of iron in a $0.10 \mathrm{~mol} \mathrm{~L}^{-1} \mathrm{Na}_{2} \mathrm{WO}_{4}$ with the addition of 0.10 mol $\mathrm{L}^{-1} \mathrm{NaCl}$, at the open circuit potential at various immersion times. After 3 and 14 days of exposure the magnitude of $\mathrm{R}_{\mathrm{p}}$ corresponds to a stable passive film, showing two overlapped time constants, corresponding to both capacitive and diffusional processes. After 28 days these time constants are weakly separated, the $\mathrm{R}_{\mathrm{P}}$ decreased, but remained very high and could not be determined at the present low-frequency limit of $10 \mathrm{mHz}$. The maximum phase angle of all diagrams, near $-45^{\circ}$, can be ascribed to a Warburg impedance.

The equivalent circuit (EC) which can be satisfactorily used for fitting the EIS diagrams of Figure 6 is $\mathrm{R}(\mathrm{CW})$, where $\mathrm{R}$ is the electrolyte resistance followed by a capacitance $(\mathrm{C})$ in parallel with a diffusional Warburg (W) impedance related to mass transport inside the pores and/ or pits and in the solution. Figure 7 shows the experimental and simulated Bode plots obtained for the iron electrode after 14 days exposure in a $\mathrm{Na}_{2} \mathrm{WO}_{4} 0.10 \mathrm{~mol} \mathrm{~L}^{-1}$ solution with the addition of $0.10 \mathrm{~mol} \mathrm{~L}^{-1} \mathrm{NaCl}$. The fitting parameters are given in Table 1. The high capacitance values found are interpreted considering that in the presence of chloride, at prolonged exposure, the film becomes more defective and porous.

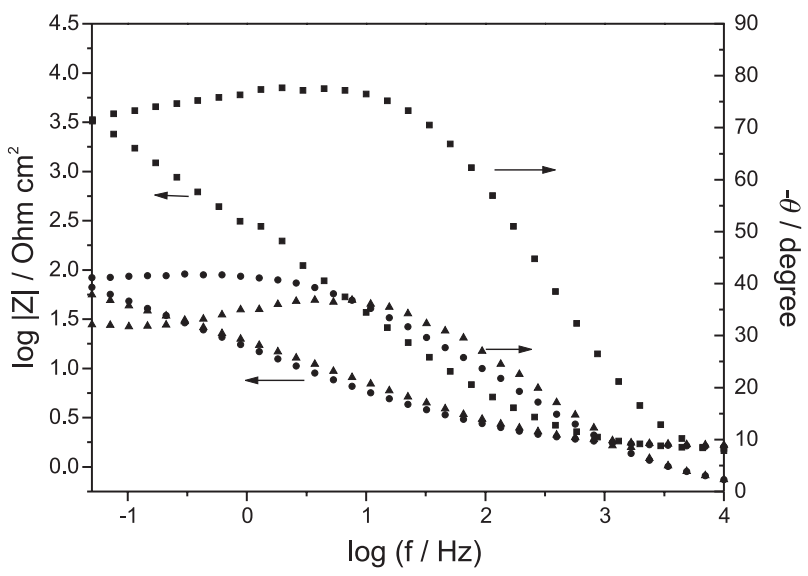

Figure 6. Effect of immersion time on the Bode diagram for $\mathrm{Fe}$ electrode in a $0.10 \mathrm{~mol} \mathrm{~L}^{-1} \mathrm{Na}_{2} \mathrm{WO}_{4}$ solution with the addition of $0.10 \mathrm{~mol} \mathrm{~L}^{-1} \mathrm{NaCl}$, at the open circuit potential, after $3(\boldsymbol{\square}), 14(\boldsymbol{\Delta})$ and 28 (ays of exposure.

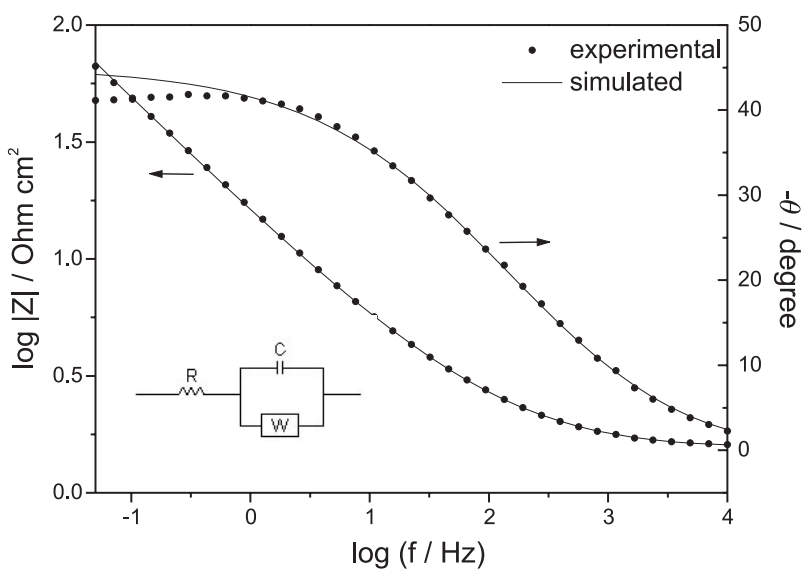

Figure 7. Experimental $(\bullet)$ and simulated $(-)$ Bode diagrams for Fe electrode in a $0.10 \mathrm{~mol} \mathrm{~L}^{-1} \mathrm{Na}_{2} \mathrm{WO}_{4}$ solution with the addition of $0.10 \mathrm{~mol} \mathrm{~L}^{-1} \mathrm{NaCl}$, at the open circuit potential, after 14 days of exposure.

Table 1. Fitting parameters used to simulate the EIS data for $\mathrm{Fe}$ given in Figure 7

\begin{tabular}{cccc}
\hline $\begin{array}{c}\text { Exposure Time } \\
\text { (days) }\end{array}$ & $\mathrm{R}$ & $\begin{array}{c}\mathrm{C} \\
\left(\Omega \mathrm{cm}^{2}\right)\end{array}$ & $\begin{array}{c}\mathrm{W} \\
\left(\mathrm{F} \mathrm{cm}^{-2}\right)\end{array}$ \\
\hline 2 & 1.726 & 251 & $\left.0.361 \times 10^{-3}\right)$ \\
14 & 1.578 & 383 & $0.262 \times 10^{-1}$ \\
28 & 1.798 & 739 & $0.281 \times 10^{-1}$ \\
\hline
\end{tabular}


Similar experiments were carried out with the AISI 304 steel by immersing this electrode at longer exposure times (9 and 27 days) in a $0.10 \mathrm{~mol} \mathrm{~L}^{-1} \mathrm{Na}_{2} \mathrm{WO}_{4}$ with $0.10 \mathrm{~mol} \mathrm{~L}^{-1}$ $\mathrm{NaCl}$ can be seen in Figure 8. No significant changes were evidenced on the corrosion behaviour, but the capacitance showed a lower value, around $17 \mu \mathrm{F} \mathrm{cm}^{-2}$, the polarization resistance corresponds to a passive film, and in both cases, the $\mathrm{E}_{\text {corr }}$ remained close to $0 \mathrm{~V}$.

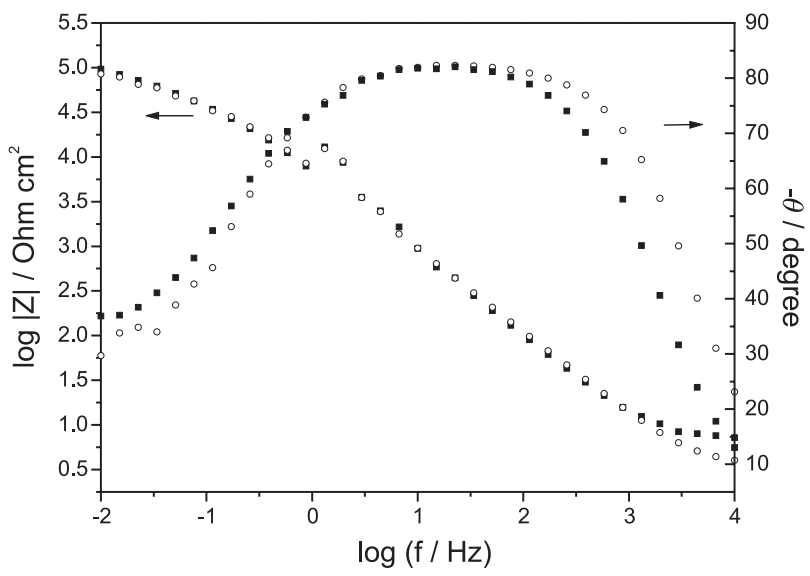

Figure 8. Effect of immersion time on the Bode plots for AISI 304 steel in a $0.05 \mathrm{~mol} \mathrm{~L}^{-1} \mathrm{Na}_{2} \mathrm{WO}_{4}$ solution with the addition of $0.10 \mathrm{~mol}$ $\mathrm{L}^{-1} \mathrm{NaCl}$, at the open circuit potential, after $9(\mathrm{O})$ and $27(\boldsymbol{\square})$ days of exposure.

The diagrams are characterized by two overlapped capacitive loops in the high and middle frequencies, which may related to an adsorption process on the electrode surface ${ }^{16,20}$ followed by a diffusional loop at lower frequencies. Moreover the diffusional contribution to the overall process decreased at prolonged exposure time.

The EIS data were fitted by an equivalent circuit $R_{s}\left(C_{f}\left[R_{f}\left(R_{a d} C_{a d}\right)\right]\right)$, which has been proposed for electrode reactions with strongly adsorbed species. ${ }^{14,16,20}$ The experimental and simulated diagrams for the AISI 304 after 27 days immersion are showed in Figure 9. In this circuit, $R_{S}$ represents the electrolyte resistance, $C_{f}$ and $R_{f}$ the capacitance and resistance of the film, $\mathrm{C}_{\mathrm{ad}}$ and $\mathrm{R}_{\mathrm{ad}}$ the capacitance and the resistance related to the adsorbed species. The proposed circuit for the EC shows two time constants, the one for the adsorbed species $\left(\mathrm{R}_{\mathrm{ad}} \mathrm{C}_{\mathrm{ad}}\right)$ being higher than that for the film $\left(\mathrm{R}_{\mathrm{f}} \mathrm{C}_{\mathrm{f}}\right)$. The high capacitance values were attributed to a porous film in agreement with the experimental data. The fitted parameters (Table 2) indicate that the formed film remained stable in this medium, despite the prolonged exposure time in chloride containing solution.

Previous studies related to the inhibition effect of tungstate was performed at static conditions by employing potentiostatic $^{8,9}$ and X-ray photoelectron spectroscopy

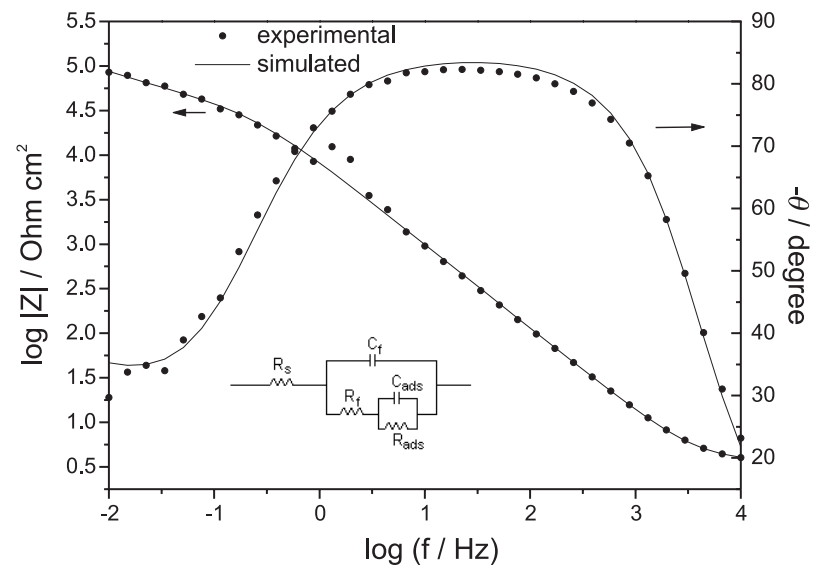

Figure 9. Experimental $(-)$ and simulated $(-)$ Bode diagrams for AISI 304 steel electrode in a $0.05 \mathrm{~mol} \mathrm{~L}^{-1} \mathrm{Na}_{2} \mathrm{WO}_{4}$ solution with the addition of $0.10 \mathrm{~mol} \mathrm{~L}^{-1} \mathrm{NaCl}$, at the open circuit potential, after 27 days of exposure.

Table 2. Fitting parameters used to simulate the EIS data for AISI 304 steel given in Figure 9

\begin{tabular}{cccccc}
\hline $\begin{array}{c}\text { Exposure } \\
\text { Time (days) }\end{array}$ & $\begin{array}{c}\mathrm{R}_{\mathrm{s}} \\
\left(\Omega \mathrm{cm}^{2}\right)\end{array}$ & $\begin{array}{c}\mathrm{C}_{\mathrm{f}} \\
(\mu \mathrm{F} \mathrm{cm})\end{array}$ & $\begin{array}{c}\mathrm{R}_{\mathrm{f}} \\
\left(\mathrm{k} \Omega \mathrm{cm}^{2}\right)\end{array}$ & $\begin{array}{c}\mathrm{C}_{\mathrm{ad}} \\
\left.(\mu \mathrm{F} \mathrm{cm})^{-2}\right)\end{array}$ & $\begin{array}{c}\mathrm{R}_{\mathrm{ad}} \\
\left(\mathrm{k} \Omega \mathrm{cm}^{2}\right)\end{array}$ \\
\hline 9 & 7.82 & 14.76 & 23.52 & 52.6 & 77.8 \\
27 & 4.10 & 15.67 & 25.48 & 56.8 & 62.2 \\
\hline
\end{tabular}

(XPS) ${ }^{6}$ The potentiodynamic and EIS measurements performed in this work showed some aspects concerning the passive film stability and the effect of mass transport on the corrosion process. The experimental data obtained at the open circuit potential and under polarization for the iron and AISI 304 steel electrodes in tungstate solutions evidence that the tungstate anion can be used to improve the film resistance and hinder the pit propagation process. These results open promising possibilities for the development of inhibitor mixtures, with an enhanced inhibitive action. Studies about the inhibition efficiency employing lower tungstate concentration solutions are in course in our laboratory.

\section{Conclusions}

By comparing the results obtained in this study, it is possible to conclude that the inhibitive action of tungstate anion is related to its adsorption on the metal surface, being dependent on the presence of dissolved oxygen. This behavior can be attributed to the lack of a powerful oxidizing property of the tungstate anion. In conditions of enhanced mass transport and in chloride-containing solution a competitive process takes place.

Under anodic polarization, at lower sweep rate and 
electrode rotation pit nucleation is inhibited. On increasing the sweep rate, the tungstate inhibition efficiency decreases independently on the electrode rotation. Thus, the increased protective nature of the passive films results from the adsorption of tungstate anions on the film defects, decreasing the metal dissolution and suppressing the pit propagation. For stainless steel pitting potentials are easily related to chloride concentration and to mass transport. For rotated electrodes nucleation is inhibited.

At the open circuit potential, the EIS data have clearly demonstrated that the magnitude of the corrosion resistance decrease is dependent on the inhibitor/aggressive anion concentration ratio. On increasing the immersion time in tungstate solution the protective action is considerably improved. It seems that the passive film may repair itself at longer exposure time, due to a sealing process, increasing the film stability. This feature can be related to a stronger adsorption of tungstate anion on the metal surface, by repairing the defects of the passive film and within the pit, and also, acting as a buffer preventing the local acidification.

\section{Acknowledgments}

Financial support of this work by Brazilian agencies: CNPq, and FAPERGS, are gratefully acknowledged.

\section{References}

1. Hoar,T.P.; Evans, U.R.; J. Electrochem. Soc. 1952, 99 , 212 .

2. Pryor, M. J.; Cohen, M.; J. Electrochem. Soc. 1953, 100, 204.

3. Sympson, R.F.; Cartledge, G.H.; J. Electrochem. Soc. 1956, 60, 1037.
4. Rajagopalan, K.S.; Venkatachari, G.; $4^{\text {th }}$ European Symposium on Corrosion Inhibitors Proceedings, Italy, 1975.

5. Kolman, D.G.; Taylor, S.R.; Corrosion 1998, 49, 622 .

6. Fujioka, H.; Nishihara,K.; Aramaki; Corros. Sci. 1996, 38, 1915.

7. Martini, E.A.; Piatnicki, C.M.S.; Azambuja, D.S.; Muller, I.L.; Electrochemical Methods in Corrosion Research. Proceedings. Hungary, 2000. CDRoom.

8. Abd El Kader, J.M.; El Warraky, A.A.; Abd El Aziz, A.M.; Brit. Corros. J. 1998, 33, 139.

9. Abd El Kader, J.M.; El Warraky, A.A.; Abd El Aziz, A.M.; Brit. Corros. J. 1998, 33, 145.

10. Pourbaix, M.; Atlas d'Équilibres Életrochimiques, GauthierVillars \& Cie Éditeur-Imprimeur-Libraire: Paris, 1963.

11. Drogowska, M.; Ménard, H.; J. Appl. Electrochem. 1996, 26, 217.

12. Isaacs, H.S.; Corros. Sci. 1989, 29, 313.

13. Sharland, S.M.; Corros. Sci. 1987, 27, 289.

14. Walter, G.W., ; Corros. Sci. 1986, 26, 681.

15. Lorenz,W.L.; Mansfeld, F; Electrochim. Acta 1986, 31, , 467.

16. Mansfeld, F.; Electrochim. Acta 1993, 38, 1891.

17. Magalhães, A.A.O. ; Margarit, I.C.P. ; Mattos,O.R.; Electrochim. Acta 1999, 44, 4281

18. Cotton, F.A.; Wilkinson, G.; Advanced Inorganic Chemistry, $5^{\text {th }}$ ed., John Wiley and Sons: New York, 1988.

19. Sakashita , M.; Sato N.; Corros. Sci. 1977, 17 , 461.

20. Juttner, K.; Electrochim. Acta 1990, 35, 1501.

Received: February 3, 2003

Published on the web: August 12, 2003 